\title{
Research On The Construction Of Education Service Platform Based On Cloud Computing
}

\author{
Liucheng Zhang ${ }^{1, a}$ \\ ${ }^{1}$ The practice teaching management center,Harbin University of Commerce,Harbin,China \\ azhangliucheng@126.com
}

Keywords: cloud computing advantage education; service platform; construction

\begin{abstract}
This paper based on the cloud computing technology. Analysis of cloud computing in education service platform construction, discuss the combination of cloud computing and education, expounds the significance of the construction of the service platform for education, and discusses the related problems based on the cloud computing education service platform construction is proposed based on the cloud computing education services platform to build the preliminary conception, in order to adapt to the new development in the field of education.
\end{abstract}

\section{Introduction}

Education service platform based on cloud computing is a dedicated to education in the field of cloud computing service platform, breaking the traditional mode of education, introduced a new concept of education informatization, learning, communication, teaching, management is an organic whole, make the students, teachers, schools, education institutions, and other education workers to break the limit of time and space to achieve the same platform, communication and resource sharing. Education service platform based on cloud computing is mainly supported by cloud computing, and build a intelligent education basic education information management platform, centering on the resource integration, integrated into the learning, teaching, management, and other areas of the work, realize the education resource sharing, improve education resource utilization, finally promote the development of the education teaching mode reform.

\section{Cloud computing related concepts}

Cloud computing, a kind of distributed computing technology, the most basic concept is through the network will be a huge computational processing program automatically split into numerous smaller subroutines, and make a vast system composed of multiple server by search, analysis and calculation after will handle the results back to the user. Cloud computing is a pattern to use pay. This model provides available, convenient, according to the requirements of network access, into allocation of computing resources shared pool, these resources can be quickly provided, just put a few management work, and service providers with little interaction. The nature of cloud computing is to ensure that users can use a lot of cloud computing resources, including CPU and memory, without need to purchase their own equipment, that can access and processing information anytime and anywhere, and can easily share information with others.

\section{Application of cloud computing in the field of Education}

China cloud computing industry have good potential for development, the development of cloud computing with the law of development of science and technology in general, need to have a from the thought of the key technology breakthrough, and finally to the demonstration of the application, finally to large-scale promotion of the process. China is the largest population in the world, the core idea of cloud computing is the large-scale data storage, processing capacity of public utilities, into millions of households. These years, China's rapid economic development, to support the construction of cloud computing infrastructure provides a strong economic base. 
Cloud Computing Assisted Instruction.Cloud Computing Assisted Instruction (Cloud Computing Assisted instructions, CCAI) is refers to the schools and teachers using "cloud computing" to support the education of "cloud service", individualized teaching information environment construction, support teachers effective teaching and the students' active learning, promote the students' thinking ability of senior and collective intelligence development, improve the quality of education. It is to make full use of cloud computing brings cloud services we provide for the sharing of teaching resources, convenient conditions for unlimited storage space.

Cloud Computing Assisted Education.Cloud Computing Assisted Instruction (clouds computing based education, CCBE), or "based on cloud computing education" refers to in all the fields in education, the use of cloud computing services to assist the education and teaching activities. Cloud computing is an emerging discipline concept education assistance, belongs to the cross field of computer science and science education. It focuses on cloud computing the sum of all elements from the era of educational activities in the future, mainly explores the application of cloud computing services in education and teaching in the, and the mainstream learning theory support and fusion, corresponding educational and teaching resources and the process of design and management.

\section{The construction of education service platform based on Cloud Computing}

In today's information technology, cloud computing based education services platform has a bright future, has a broad market development, great potential. Education service platform based on cloud computing for the majority of users provides a comprehensive quality education platform, to realize the sharing of resources, and on the basis of Educational Metropolitan area network, in the construction of "the relative concentration of" ideas of education metropolitan area network application service planning. It uses advanced cloud technology (64 bit flexible structure) and education depth integration, innovative education model (collaborative education), to achieve the balance of education, for the fair education services.

The construction method of education service platform based on Cloud Computing.using cloud computing to support cloud education platform, high efficiency, high quality of supporting daily teaching

\section{Create information resources circulation environment.}

Education is the core of educational resources, the network education resources construction needs a large number of educational resources, including investment in human resources, information resources and knowledge resources, so we have to help schools and enterprises etc. in various aspects of cooperation can play their respective advantages, the development of the network educational resources of high quality. The use of advanced virtualization technology to integrate the basic resources of the whole network education, through the virtual platform to the physical server virtual into a number of isolated virtual machine running different systems in different virtual machines. The basic physical platform to realize the sharing of multi resource system. In basic teaching conditions, to realize the standardization, marketization and industrialization, the experience and resources more unimpeded sharing and circulation, to ensure positive interaction between students and teachers. At the same time, promote the development of students' thinking ability and group intelligence, and reduce the unnecessary waste of resources.

Help users to filter out useful information.Through the comprehensive consideration of the traditional education, re planning and deployment, operation to provide solid support for the platform. In the cloud management platform, business review of education, to distinguish between key applications and non critical applications. In the education service platform of cloud computing in the accurate positioning of every user's needs and formulate corresponding plans based on data. To improve the utilization rate of resources and simplified frame effectively help users save time and manpower cost.

To reduce the use of cost, to achieve full network education resource fair sharing.Distribution of educational resources between urban and rural areas are this is the problem,so we should be more committed to reduce the cost of education resources through existing technology, users of 
underdeveloped areas provide the same educational resources sharing, people-oriented, in cloud services platform to promote all exchange area resources so as to realize the covering the same learning environment.

To expand the platform influence, so that the platform to better serve the whole community.Through simple and effective measures to make the platform to all fields, and obtain more user support and trust, so that more resources into the system, so that the system of universal, large-scale, better service society.

The organic combination of computer science and educational science to provide human services.Using high technology to create a good information environment, so as to achieve the use of teaching resources and download or exchange of experience, can allow users to feel more humane in the use of services.

Based on cloud computing platform to build the advantages of education services.

The integration of resources, improve efficiency.Education cloud platform through a simple and easy to use resource management software, to achieve resource push, search, publish, review, upload, download and other functions of a key, and effectively improve the utilization of educational cloud resources. A survey shows that more and more users have begun to transfer the data center to the virtual environment.

Through the cloud computing technology is easy to be integrated by excellent educational resources of the whole society, so that it is readily available, reducing the cost of transportation, hardware and other, fully embodies the cloud place anywhere. When the cloud computing service model from the concept of training, to the present education cloud platform has shown signs of emerging, as if "suddenly, such as spring night", so that domestic enterprises to obtain a large number of users of information. Currently, throughout China's cloud computing industry, is entering a comprehensive take-off period, Cloud Applications gradually landing. Cloud technology allows business users to more cost savings, more efficient.

Strong interaction.Teachers use education cloud platform of education the teaching environment of network and information, while satisfying the whole class interactive teaching, group cooperative learning, students with personalized learning a variety of teaching environment. By designing a includes classroom activity design, interactive learning, cooperative learning, classroom feedback and other functions as well as providing learning resources and the content of cross platform system software, using handheld learning terminal wireless mobile terminal equipment, collaborative classroom, virtual classroom platform hardware tool to realize the function of the software system, improve the real-time interaction between teachers, students and parents, and to maximize the efficiency of teaching.

Update speed.In this era of diversification and efficiency of information, the timeliness and accuracy of resources is undoubtedly one of the main advantages of the cloud platform. Education cloud platform through cloud technology can be collected from a variety of channels at the same time a lot of information and real-time push to online users, effectively accelerate the speed of information dissemination.

\section{Conclusions}

Government attaches great importance to the development of science and technology and the use of science and technology to promote economic and social development, support the development of cloud computing, but also the government's policy has been highly recognized by the whole society. We have also aroused great attention from the business sector, we are now a lot of private enterprises is the leading enterprise of our cloud computing, which is a favorable aspect.

Education service platform based on cloud computing can not only solve the problem of data interoperability and eliminate information island and realize the integration and sharing of resources, and can flexibly deal with the future development needs, and based on this platform, the development and change of demand for rapid development of construction of a rich variety of educational 
applications, and ensure that the application of organic unity, integrated innovation, to play the maximum benefit.

Overall cloud storage for educational information flow in improving teaching efficiency and reduce the investment of resources and promote the stability of the system at the same time, increase the risk of privacy infringement and safe storage of flow and the urgent need for the adoption of statutory involved the scope of personal information, build education information transfer and internal supervision mechanism, unified cloud service agreement required clauses, the establishment of data rights expressly agreed rules, establish a complete system of tort liability, improved the cloud service provider of security barriers and improve the cognitive level of educational institutions and stakeholders coping strategies, gradually formed a healthy and orderly cloud storage flow environment, promote the education informationization, industrialization and modernization.

In short, the education cloud should seize the current trend, the integration of more advantage of the resources in the cloud, which is the current trend of education development.

\section{Acknowledgements}

This work was financially supported by the Natural Social Science Foundation (15BJY017). National-level Project of College Student's Innovative and Entrepreneurial Training Program,Code of Project: 201510240001

\section{Reference}

[1] [Li Hua. The concept of cloud computing cloud based on the discussion on education. 《Journal of Tianjin Radio \&amp; TV University》, 2011, 15 (3): 47-50

[2] Liu Yunpo . The analysis of advantages and disadvantages of the integration of information technology and mathematics curriculum. 《Journal of Chengdu Institute of education》, 2005, 19 (6): 101-101

[3] Gao Yuan, College students' innovative entrepreneurial training plan of project process management research and exploration [J], Journal of laboratory science, 2013 (6), pp. 71-74.

[4] Yang Weizhi, Using the simulation system to cultivate students ability of enterprise management [J], Journal of laboratory research and exploration, 2013, no. 4, pp. 11-13.

[5] Zhang Li,Applied talents cultivation of innovative thinking mode exploration [J], China's higher education, 2012, (19) , pp.12-13

[6] Chen Yinping, Yin Long, College students' innovative entrepreneurial training plan to carry out the practice and exploration, in Harbin university of commerce, for example [J], Journal of new economy, 2014,(15) , pp. 41-54.

[7] Si Songmen, Zhuang Yale, Thinking about college students' innovative entrepreneurial training program [J], Journal of heilongjiang education (higher education research and evaluation), 2014, (7) , pp. 31-33.

[8] Zhang Li. Exploration of innovative thinking mode of application oriented personnel training,.2012 (19).62-63 of higher education in China

[9] Zhang Li. Deepen the reform of practical teaching to enhance students' Entrepreneurship and innovation ability. Laboratory research and exploration.2010 (3)

[10] Zhang Li.The design of the company to create and operate the practice program design. Laboratory science.2009 (5).171-172 